\title{
A abordagem tecnogênica: reflexões teóricas e estudos de caso
}

\section{The technogenic approach: theoretical reflections and case studies}

\author{
Erika Cristina Nesta Silva $^{\text {ab }}$, Marcel Bordin Galvão Dias ${ }^{\text {ac }}$, Dener Toledo Mathias ${ }^{\text {ad }}$ \\ ${ }^{a}$ UNESP, Faculdade de Ciências e Tecnologia, Campus de Presidente Prudente \\ berikanesta@yahoo.com.br, cmbgdias@gmail.com, ddenertm@yahoo.com.br
}

\begin{abstract}
RESUMO
O desenvolvimento das técnicas e os avanços no campo científico possibilitaram a ampliação da capacidade interventora das sociedades sobre os ambientes, modificando-os de acordo com as demandas por recursos necessários à sua sobrevivência. Tal capacidade está relacionada às características sociais, políticas, econômicas e culturais dos diferentes grupos humanos. Dada a magnitude das intervenções antrópicas nas paisagens, observam-se inúmeras alterações nas dinâmicas e processos naturais, especialmente aqueles relacionados ao relevo e aos solos. A materialização destas modificações pode ocorrer, entre outras formas, através da gênese de depósitos tecnogênicos, constituídos por materiais sedimentares acrescidos de artefatos diversos, produto das diferentes atividades humanas desenvolvidas ao longo do processo histórico. Em áreas urbanas, estes depósitos têm sua gênese relacionada ao uso-ocupação do solo, considerando-se as práticas realizadas no intuito de adequar as características do meio físico às necessidades dos citadinos. Estas práticas resultam, por vezes, na instalação de um quadro de degradação ambiental, caracterizado pela ocorrência de erosão antrópica, assoreamento, disposição inadequada de resíduos sólidos, entre outros. Sob essa perspectiva, este trabalho objetiva retratar a ação antrópica e seus desdobramentos sobre o ambiente urbano, materializados por meio da formação dos depósitos e coberturas tecnogênicas. Para tanto, elegeram-se três áreas de estudo localizadas nos municípios de Goiânia (GO), São Pedro (SP) e Presidente Prudente (SP), visto que estas localidades apresentam similitudes quanto à formação de depósitos e coberturas tecnogênicas relacionados ao uso-ocupação do solo, possibilitando uma análise comparativa entre os diferentes contextos socioambientais.
\end{abstract}

Palavras-chave: Ação antrópica; Uso e ocupação do solo; Depósitos e coberturas tecnogênicas.

\begin{abstract}
The development of the techniques and the advance in the science field allowed the amplification of society's intervener capacity upon the environments, modifying them according to the demand of resources necessary to their survival. Such capacity is related to social, political, economic and cultural characteristics of the different human groups. As a result of the man-made interventions on the landscapes, numerous alterations are observed in the natural dynamics and processes, especially those related to the relief and the soil. The materialization of these modifications may occur, among other forms, through the genesis of technogenic deposits, sedimentary materials, increased by diverse artifacts, which are the product of different human activities developed along the history process. In urban areas these deposits have their genesis related to the use and occupation of the soil, considering the practices accomplished in order to adequate the characteristics of the physical environment to the necessities of citizens. These practices sometimes result in the establishment of an environmental degradation characterized by the occurrence of man-made erosion, siltation, and inadequate disposition of solid residues, among others. In view of such perspective this paper aims to portray the man-made actions and their unfolding upon the urban environment, materialized through the formation of the technogenic coverage and deposits. In order to reach this aim, three areas of study were chosen and they are located at the city council of Goiânia (GO), São Pedro (SP) and Presidente Prudente (SP), once these locations present similitude concerning to the formation of technogenic coverage and deposits related to the use and soil occupationallowing a comparative analysis among the different socioenvironmental contexts.
\end{abstract}

Keywords: Man-made action; Use and soil occupation; Technogenic coverage and deposits.

\section{Introdução}

O desenvolvimento das técnicas e a complexificação da sociedade ampliaram a capacidade interventora do
Homem sobre as dinâmicas da natureza, atribuindo-lhe o papel de agente geológico-geomorfológico. A magnitude e intensidade da ação antrópica sobre as dinâmicas da natureza variam no tempo-espaço, de 
acordo com os diversos arranjos socioambientais e o nível de desenvolvimento dos diferentes grupos sociais. Deste modo, a ação antrópica produz efeitos diversos, especialmente em áreas urbanas, nas quais estes se ampliam e diversificam. A formação dos depósitos tecnogênicos é um exemplo da ação antrópica sobre a fisionomia e a fisiologia da paisagem, uma vez que estes materiais são constituídos a partir da remoção de sedimentos pela ação antrópica (direta ou indireta).

Nos ambientes urbanizados, a gênese destes depósitos está associada à forma de apropriação dos compartimentos geomorfológicos e ao modelo de urbanização vigente. Historicamente, as cidades edificaram-se em áreas aplainadas, situadas nas proximidades de canais de drenagem, utilizados como principal fonte de abastecimento. Com o desenvolvimento social e o estabelecimento de estratos socioeconômicos distintos, a forma como os grupos sociais se relacionam e se apropriam dos elementos naturais se modificou. Associado a este fato, o crescimento vertiginoso das cidades brasileiras, em decorrência de transformações na estrutura social, econômica e política ocorrida a partir dos anos de 1960, resultou na adoção de um modelo de urbanização, por vezes, indiferente às capacidades e fragilidades do meio físico local.

Em diversos municípios brasileiros, a ocupação de áreas ambientalmente vulneráveis, associada à inexistência ou precariedade de infraestrutura e serviços urbanos (sistema de microdrenagem, arruamentos, saneamento básico, coleta e tratamento dos resíduos sólidos) e alguns hábitos da população, como as queimadas, o lançamento de resíduos sólidos domésticos e entulho em terrenos baldios e nos fundos de vale, colaboraram para a instalação de um quadro de degradação socioambiental. Assim, observa-se na atualidade a ocorrência de diversos problemas ambientais urbanos, especialmente aqueles relacionados à qualidade do ar, das águas e do solo, a exemplo do assoreamento e contaminação dos cursos d’água pelo lançamento de resíduos sólidos e efluentes, e a degradação dos solos pela erosão antrópica acelerada, em áreas urbanas e rurais, devido à retirada da cobertura vegetal e às práticas inadequadas de uso e manejo do solo, sobretudo em atividades econômicas como agricultura e pecuária.

Dada a complexidade das dinâmicas sociais e naturais, a identificação e caracterização dos depósitos tecnogênicos possibilita o entendimento acerca da intervenção humana sobre a natureza e suas dinâmicas, constituindo-se em marcos estratigráficos (Peloggia 1996) na paisagem. A composição dos materiais tecnogênicos está diretamente relacionada à ação antrópica desenvolvida num dado ambiente, contendo, assim, materiais autóctones, sedimentos remobilizados e artefatos manufaturados diversificados.

O texto apresenta inicialmente uma revisão teórica sucinta sobre as modificações da paisagem pelo Homem, enfocando aspectos relacionados à dinâmica geológica e geomorfológica. A revisão não pretende esgotar o assunto, mas busca, fundamentada na bibliografia existente, oferecer um suporte à compreensão de seus aspectos fundamentais.

Posteriormente, são apresentados três estudos de caso, tomados como representativos por suas especificidades espaciais e processuais, seguidos de uma análise comparativa, identificando as similitudes e diferenças entre as áreas eleitas. Nesse sentido, o presente artigo apresenta algumas considerações sobre o tema, bem como estudos de caso que provêm de um esforço metodológico para a análise dos fenômenos abordados. Considera-se que tais estudos constituem contribuição importante para a ampliação do conhecimento sobre as formações tecnogênicas.

\section{Aspectos teóricos acerca das modificações da paisagem pelo Homem}

A alteração das dinâmicas da natureza pela sociedade vem sofrendo contínua aceleração, iniciada a partir da primeira grande Revolução Agrícola, momento em que o ser humano sedentariza-se, fixando-se à terra e cultivando-a para seu sustento. Assim, inicia-se um processo de alteração das condições naturais, a começar pela conversão de florestas em pastagens e áreas de cultivo, no intuito de facilitar a instalação dos grupos humanos e possibilitar a extração dos recursos necessários à sua sobrevivência.

O desenvolvimento socioeconômico e a evolução progressiva da ciência e da técnica foram acompanhados pela crescente demanda por recursos naturais, gerando inúmeros desequilíbrios ambientais. Esses desequilíbrios são produtos da ampliação da capacidade interventiva e transformadora da sociedade sobre a natureza, alterando suas dinâmicas e processos no intuito de aperfeiçoar as condições necessárias à sua existência.

De modo geral, a ação antrópica e suas consequências sobre os ambientes podem ser compreendidas e observadas a partir de diferentes níveis de abordagem, considerando-se as formas, processos e depósitos superficiais existentes no ambiente. Conforme Peloggia (1998), baseado em Ab’Saber (1969), a ação antrópica é capaz de promover alterações no relevo e nas demais características fisiográficas da paisagem, bem como modificações na fisiologia desta e a criação de depósitos correlativos comparáveis aos quaternários.

A compreensão das alterações promovidas pela ação antrópica nas paisagens constitui tema relevante nos estudos realizados no âmbito da Geologia e da Geomorfologia do Quaternário. A magnitude e intensidade destas alterações em termos geológicos justificam a premissa de que a sociedade configura-se como agente ativo nos processos superficiais. Segundo Peloggia (2005), os efeitos da ação antrópica possuem magnitude, por vezes, superior àqueles resultantes da dinâmica natural. Considerando-se a expressão da ação antrópica na superfície terrestre, que abrange grandes extensões de terras em diferentes domínios climáticos, transformando os ambientes por meio da agricultura, 
do extrativismo ou da expansão dos núcleos urbanos, tem-se condição suficiente para afirmar que os processos geológicos e geomorfológicos estão sujeitos ao condicionante tecnogênico, justificando a adoção de uma nova abordagem a respeito da dinâmica dos processos superficiais.

A ação geológica e geomorfológica da sociedade inclui a capacidade de modificação dos materiais de cobertura superficial e, em consequência, a potencialização dos processos erosivos. Outro ponto fundamental é que a ação antrópica não ocorre de igual maneira em toda a superfície terrestre, pois depende de fatores diversos. A esse respeito, Nir (1983) coloca a existência de fatores fundamentais, como a demografia (considerando-se que as possibilidades de intervenção nas paisagens não são iguais a todas as pessoas), o fator histórico, o econômico, relacionado às novas tecnologias e ao investimento de capital, e o socioeconômico, no qual diferentes padrões de vida envolvem diversificadas formas de intervenção nos processos naturais.

Apesar de a capacidade de modificação da superfície terrestre pela sociedade ter se acentuado no período da Revolução Industrial, o início das transformações, mesmo que de modo menos intenso, pode ser atribuído à Revolução Neolítica, há aproximadamente 10.000 anos “[...] quando o Homem conquista as primeiras técnicas de produção de alimentos, deixando sua fase de coletor, na qual não se destacava do conjunto de atividades biológicas nas suas relações com a natureza" (Oliveira 1990, p.412). O início da revolução agrícola no período Neolítico representa, também, o início de um novo período na escala do tempo geológico: o Quinário ou Tecnógeno.

Segundo Peloggia (2003), há uma diferença quanto à denominação “Quinário” e “Tecnógeno”. Quinário implica em estatuto de sistema, representando, desta forma, um período, indicativo de posição estratigráfica em sequência - superior ao Quaternário e ao Terciário. A denominação Tecnógeno implica em menos problemas formais, devido ao fato de a riqueza de referência estar no conteúdo material, incluída como série, representando uma época do Quaternário ou Antropógeno (Peloggia 2003, grifo nosso).

A transição do Quaternário para o Quinário é gradual em todo o planeta, de acordo com a intensidade da ação humana transformadora da natureza e o aparato técnico disponível para sua concretização. Ainda, segundo Oliveira (1990), alguns autores soviéticos têm utilizado a expressão Antropógeno em substituição ao Quaternário, no intuito de identificar o período geológico mais recente marcado pela evolução do Homem. Os eventos antropogênicos seriam, portanto, relacionados a este período geológico, podendo ser, ou não, ligados às atividades humanas. Assim, é preferível utilizar a expressão “Tecnogênico” para definir eventos relacionados às atividades do Homem (Oliveira 1990). Além disso, Oliveira (1990, p.412) aponta que o "termo tecnogênico destaca a importância em se considerar que os eventos resultantes da ação humana refletem uma ação técnica e, neste aspecto, sua adoção tem larga vantagem sobre a do antropogênico, pois a técnica surge com o homem e marca sua evolução”.

Conforme a proposta estabelecida por Ter-Stepanian (1988), o Quinário seria um período e o Tecnógeno sua época correspondente. Rohde (2005) propõe a divisão (teórica) do Tecnógeno em duas idades ou momentos distintos, genericamente denominados Tecnógeno I e II. A inclusão dessa nova época na escala do tempo geológico considera o Quaternário representativo da evolução natural da Terra, ao passo que Quinário representa o período em que o ser humano passa a desempenhar importante papel enquanto agente geológico e geomorfológico. O Tecnógeno I, segundo o autor, é aquele de reconhecimento dos desequilíbrios provocados pela ação antrópica, bem como pode ser definido por uma etapa de migração de uma Biosfera I, de evolução natural sem interferência humana, para uma Biosfera II, modificada e criada. Já o Tecnógeno II é posterior, e nele o ser humano tenta diminuir seu impacto obtendo um novo equilíbrio dinâmico entre a Tecnosfera e a Biosfera (Rohde 2005).

A tabela 1 representa a inserção do Quinário na sequência de períodos geológicos, bem como as características inerentes a suas épocas.

Os fenômenos em que a gênese é atribuída à ação antrópica se processam através da geotecnogênese, caracterizada primeiramente, de acordo com Peloggia (2005), a partir das alterações na fisiologia das paisagens, que resultam de mudanças na dinâmica dos processos superficiais. Subsequentemente tem-se a criação de formas de relevo e formação de depósitos sedimentares. As interferências antrópicas referidas produzem, direta ou indiretamente, respostas processuais tanto degradacionais (no caso da erosão ou dos terrenos terraplanados, por exemplo) como agradacionais (assoreamento de canais ou aterros construídos). Desta forma, a ação antrópica responsável pelas alterações nas características geomorfológicas é denominada morfotecnogênese. Esta ocorre sobre circunstâncias geológicas prévias, resultando em formas de primeiro tipo (degradacionais) e formas de segundo tipo (agradacionais) (Peloggia 2005).

No tocante às formas agradacionais, especialmente aquelas localizadas em áreas urbanas, nota-se uma diversidade de materiais constitutivos relacionados aos processos de uso e ocupação do solo. Tais materiais, denominados depósitos tecnogênicos, são produtos da intervenção antrópica nas paisagens através do uso das técnicas.

Estes depósitos podem ser classificados de acordo com a gênese, composição, estrutura, forma de ocorrência e ambiente tecnogênico, de acordo com a proposta de Classificação Integrada elaborada por Peloggia (1999), conforme segue:

- O primeiro parâmetro, gênese, é composto por depósitos de primeira ordem, os quais resultam de forma direta de processos tecnogênicos (depósitos construídos, 
induzidos e modificados, conforme classificação de Oliveira 1990) e por depósitos de segunda ordem, que englobam os retrabalhados propostos por Nolasco (1998) e os remobilizados (Peloggia 1999).

Tabela 1: O período Quinário na tabela do tempo geológico

\begin{tabular}{|c|c|c|c|c|}
\hline ERA & PERÍODO & ÉPOCA & IDADE & CARACTERÍSTICAS \\
\hline \multirow{4}{*}{$\begin{array}{l}0 \\
\text { U } \\
0 \\
\text { o } \\
Z_{11} \\
\text { u }\end{array}$} & \multirow[b]{2}{*}{ QUINÁRIO } & \multirow[b]{2}{*}{ Tecnógeno } & Tecnógeno II & $\begin{array}{l}\text { Redução ou eliminação } \\
\text { dos impactos gerados } \\
\text { no Tecnógeno I }\end{array}$ \\
\hline & & & Tecnógeno I & $\begin{array}{l}\text { Eclosão dos } \\
\text { desequilíbrios } \\
\text { ambientais gerados pela } \\
\text { efetuação humana } \\
\text { alopoiética; criação da } \\
2^{a} \text { natureza; passagem } \\
\text { da Biosfera I para } \\
\text { Biosfera II; início por } \\
\text { volta de } 10.000 \text { AP }\end{array}$ \\
\hline & $\begin{array}{l}\text { ANTROPÓGENO } \\
\text { (QUATERNÁRIO) }\end{array}$ & & & \\
\hline & $\begin{array}{c}\text { NEÓGENO } \\
\text { (TERCIÁRIO } \\
\text { SUPERIOR) } \\
\text { PALEÓGENO } \\
\text { (TERCIÁRIO } \\
\text { INFERIOR) }\end{array}$ & & & \\
\hline
\end{tabular}

- O segundo parâmetro é a composição, que varia de acordo com a presença de materiais úrbicos, gárbicos, espólicos e líticos. No caso dos depósitos induzidos, nos quais a influência antrópica ocorreu somente nos processos e sendo o material constituinte principalmente natural, tem-se a categoria sedimentar. Com relação aos depósitos constituídos por sedimentos aluviais compostos por partículas naturais e tecnogênicas, tem-se a adoção do termo tecnogênico-aluvial (Osovetskiy 1996 apud Peloggia 1999).

- $\quad$ O terceiro parâmetro, a estrutura, refere-se à organização interna dos depósitos tecnogênicos, podendo ser estratificados, acamadados, em células, maciços e irregulares.

- O quarto parâmetro é a forma de ocorrência, considerada, em alguns casos, comparável a formas de ocorrência naturais, como nas denominações aluvioformes (análogas aos aluviões) e coluvioformes (análogas aos colúvios). Outras formas de ocorrência são originais, como os maciços isolados e os lençóis de aterramento, sendo estes “[...] amplas superfícies recobertas por depósitos tecnogênicos pouco espessos, em geral antigas várzeas” (Peloggia 1999, p.39).

- O quinto e último parâmetro é o ambiente. Neste, estão presentes os ambientes industriais, mineiros, urbanos e rurais, trabalhados por Nolasco (1998) e é incluído o ambiente periurbano. A tabela 2 sintetiza a proposta de Peloggia (1999),

Nos estudos de caso apresentados neste trabalho serão utilizados na descrição dos depósitos tecnogênicos os parâmetros gênese e composição. Quanto à gênese, Oliveira (1995, p.233) classifica os depósitos tecnogênicos em três tipos principais: “construídos (aterros, corpos de rejeito etc.), induzidos (assoreamento, aluviões modernos etc.) e modificados (“depósitos" naturais alterados tecnogenicamente por efluentes, adubos etc.)", sendo esta classificação uma das constituintes da Classificação Integrada de Peloggia (1999). Quanto aos materiais constitutivos, de acordo com proposta de Fanning \& Fanning (1989), adaptada por Peloggia (1996), estes podem ser classificados em: materiais úrbicos, que compreendem materiais terrosos com artefatos manufaturados pelo homem moderno (tijolo, plásticos, vidro, asfalto, pregos e outros), materiais gárbicos, que correspondem a detritos ricos em matéria orgânica (como o lixo orgânico), materiais espólicos, que são os materiais terrosos escavados e redepositados, e materiais dragados, que correspondem aos materiais terrosos provenientes de operações de dragagem.

Os exemplos abordados nos estudos de caso são representativos do tema por apresentarem características espaciais e processuais intrínsecas às alterações promovidas pela ação antrópica na dinâmica geológica-geomorfológica. Assim, elegeram-se três áreas situadas em ambientes urbanos com diferentes contextos socioambientais, localizadas no perímetro 
Antropoceno - Tecnógeno

urbano de Goiânia-GO, São Pedro-SP e Presidente Prudente-SP (figura 1). Nestas áreas, buscou-se compreender a gênese dos depósitos e coberturas tecnogênicas e sua relação com o uso-ocupação do solo.

Tabela 2: Classificação Integrada dos Depósitos Tecnogênicos

\begin{tabular}{lllll}
\hline \multicolumn{1}{c}{ Parâmetro } & \multicolumn{1}{c}{ Gênese } & \multicolumn{1}{c}{ Composição } & \multicolumn{1}{c}{ Estrutura } & Formas de Ocorrência \\
\hline Depósito & 1. ${ }^{\text {ORDEM }}$ & Úrbicos & Estratificados & Maciços isolados \\
tecnogênico (d.t.) & Construídos & Gárbicos & Em camadas & Lençóis de aterramento \\
& Induzidos & Espólicos & Em células & Coluviformes \\
& Modificados & Líticos & Maciços & Aluviformes \\
& & & Irregulares & \\
& 2. ${ }^{\text {a ORDEM }}$ & Sedimentares & & \\
& Retrabalhados & Tecnogênico-aluviais e peri-urbanos & \\
& Remobilizados & & & \\
& & & \\
\hline
\end{tabular}

Fonte: Peloggia (1999)

\section{Estudo de caso: Jardim Fonte Nova e Setor Morada do Sol, Goiânia-GO}

O município de Goiânia está localizado na porção centro-sul do estado de Goiás e é sua capital políticoadministrativa. Possui uma extensão territorial de $721.019 \mathrm{~km}^{2}$ e uma população de 1.302 .001 habitantes, de acordo com levantamento realizado pelo Anuário Estatístico de 2012. A partir da década de 1970, experimentou um vertiginoso incremento da população urbana, acolhendo fluxos migratórios advindos do meio rural e de outras regiões do estado e do país. A necessidade de acolher a população migrante fez com o planejamento de uso e ocupação do solo urbano desconsiderasse, por vezes, as características do meio físico, resultando na gênese ou intensificação de problemas ambientais.

A região noroeste, área deste estudo, caracterizou-se, inicialmente, como área de expansão urbana da metrópole. Devido à inobservância das condições ambientais locais, os solos, em especial, foram profundamente alterados pela ação antrópica, incorporando artefatos diversos, produto das atividades desenvolvidas ao longo do processo de ocupação, resultando na formação de depósitos tecnogênicos, especialmente nas planícies aluviais que integram a rede de drenagem da área.

Em relação aos aspectos ambientais, a região está, geologicamente, situada sobre o embasamento de rochas metamórficas proterozóicas e depósitos quaternários.

Destacam-se principalmente granulitos ortoderivados (APIgaio) e granulitos paraderivados (APIgaip) subordinadamente, do Complexo Granulítico AnápolisItauçu, no trecho setentrional; e xistos, gnaisses e quartzitos do Grupo Araxá Sul de Goiás (PMa), no restante da área (Campos et al. 2003). Na área de estudo, destacam-se os granulitos anfibolitos e bandados.

O município encontra-se compartimentado em cinco unidades morfológicas: o Planalto Dissecado de Goiânia (920-950m) a nordeste, os Chapadões de Goiânia (860-900m) na região sudoeste, o Planalto Embutido de Goiânia (750-800m) na faixa central (de SE para NW), Terraços e Planícies da Bacia do Rio Meia Ponte (700-720m) e Fundos de Vale. Segundo Casseti (1992), associados a essas unidades morfológicas estão os materiais de cobertura eluviais, coluviais e aluviais. A área de estudo situa-se nos domínios do Planalto Embutido de Goiânia, no qual predominam declividades pouco acentuadas (5-10\%).

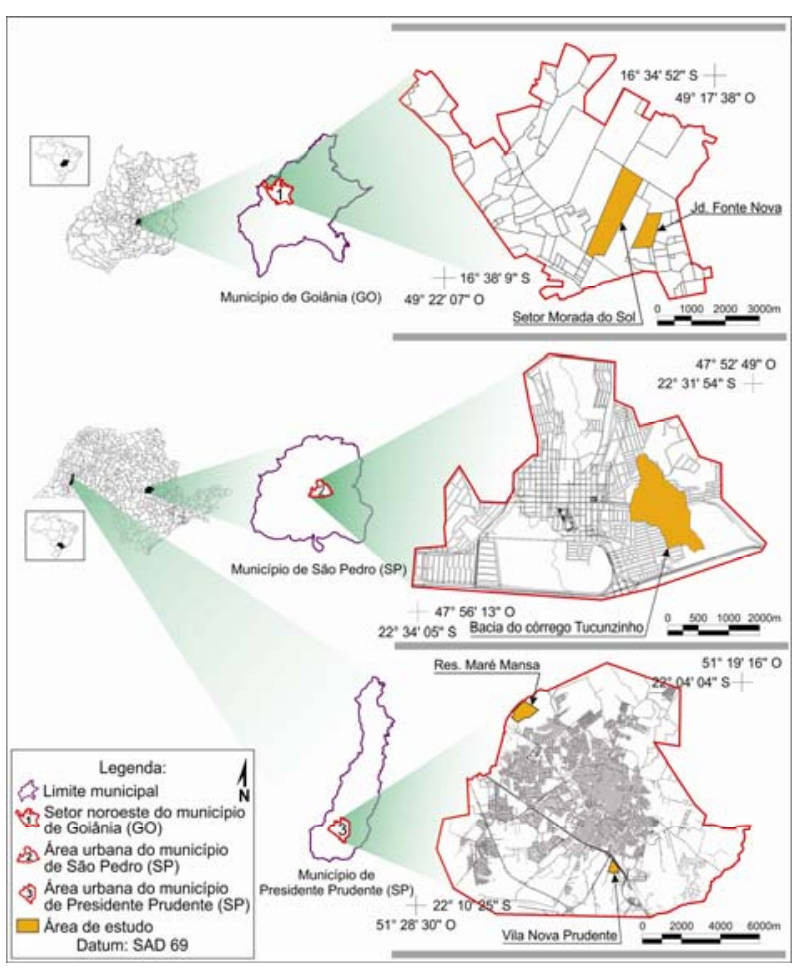

Figura 1: Mapa de localização das áreas de estudo. Org. Dener T. Mathias

Os materiais de cobertura superficial são representados por Latossolos, em geral ocorrendo em relevo plano a suave ondulado. As principais classes encontradas consistem em Latossolo Vermelho-Escuro (LVE), correspondente a aproximadamente 25,5\% da área; Latossolo Roxo (LR), originado das rochas ultrabásicas, totalizando 25,5\% da área e Latossolo Vermelho-Amarelo (LVA), correspondente a $41 \%$ da área. A área de estudo situa-se sob os domínios dos Latossolos Vermelhos (LV), entremeados por Neossolos Litólicos (RL).

$\mathrm{Na}$ área de estudo, encontram-se depósitos de primeira e segunda ordem, conforme a proposta de Oliveira et al. (2005). Os depósitos de primeira ordem enquadram-se na categoria de depósitos induzidos, pois sua origem associa-se a modificações dos processos naturais, a exemplo do assoreamento dos canais de 
drenagem por material sedimentar oriundo da erosão antrópica. Porém, daremos ênfase ao enquadramento destes materiais atentando, prioritariamente, para a sua composição e estrutura. Para tal análise, elegeram-se dois pontos representativos da gênese dos depósitos tecnogênicos na região de estudo.

O primeiro ponto localiza-se no Jardim Fonte Nova. $\mathrm{O}$ bairro tem origem recente e se localiza continuamente ao setor Alto do Vale, no sentido topovertente, de modo que a formação de depósitos nesta localidade está associada ao loteamento de ambos os bairros. Durante o processo de loteamento, o solo exposto nos lotes forneceu os sedimentos que foram carreados para as áreas de várzea, resultando em seu aterramento. Neste caso, observa-se a existência de três camadas sedimentares distintas, denominadas genericamente de 1,2 e 3 (figura 2). A camada 1 corresponde ao material detrítico remobilizado de montante, com a presença de pequenas concreções ferruginosas (lateritas), típicas da região de Cerrado. A camada 2 é constituída por material arenoso (fino), bem drenado e com pouca presença de matéria orgânica. A camada 3, por sua vez, é composta por material argiloso, mal drenada, rica em matéria orgânica, indicativo do processo de gleização, típico das áreas de várzea devido às condições de hidromorfismo.

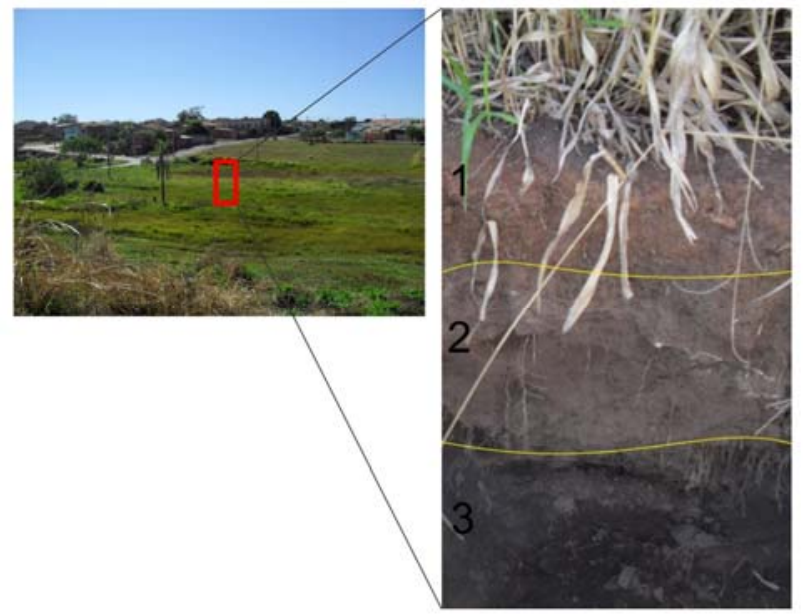

Figura 2: Depósito tecnogênico localizado no Jardim Fonte Nova, em Goiânia (GO). Fonte: Dias (2013)

O segundo ponto localiza-se no setor Morada do Sol, bairro assentado sobre a mesma vertente do Jardim Fonte Nova e dos setores Vila Finsocial e Parque Tremendão. O local situa-se às margens do córrego da Divisa, afluente do córrego Caveirinha. Esquematicamente, dividiu-se o depósito em três camadas sedimentares distintas, também denominadas genericamente 4,5 e 6 (figura 3). A camada 4 corresponde ao material remobilizado (e depositado) pela prática da terraplanagem no local e em áreas circunvizinhas. A camada 5 é constituída por materiais "úrbicos", isto é, artefatos manufaturados, tais como resquícios de construção civil (tijolos, telhas, cimento) e outros, como madeira, plásticos e metais diversos, transportados pelos fluxos de escoamento superficial das áreas de topo para a baixa vertente. A camada 6 representa a alteração provocada no aporte de sedimentos pelo uso-ocupação no entorno e a montante, resultando no assoreamento do curso d’água, modificando a dinâmica fluvial.

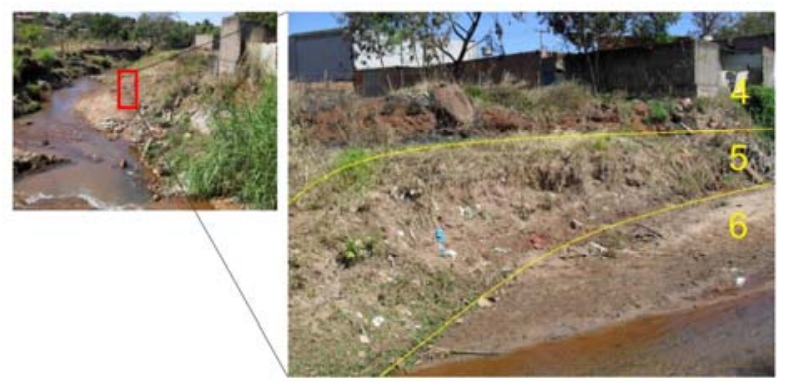

Figura 3: Depósito tecnogênico localizado no setor Morada do Sol, em Goiânia (GO). Fonte: Dias (2013)

\section{Relevos tecnogênicos e processos erosivos: a bacia do córrego Tucunzinho, São Pedro-SP}

Nos estudos que envolvem o conceito de tecnogênese são também importantes os atributos morfológicos materializados nas formas geradas pela mobilização de coberturas superficiais. Peloggia (1998) atribui a tais feições a designação de relevos tecnogênicos. Como exemplo, citam-se os terraços em nível, comumente empregados como técnica mecânica para manejo do solo em áreas agrícolas.

O terraceamento é apontado como intervenção imprescindível ao controle da erosão, dado que permite o disciplinamento da água do escoamento superficial mediante a quebra da energia do fluxo e o estímulo à infiltração (Bertoni \& Lombardi Neto 1999). No caso específico dos processos erosivos lineares, a concepção de terraços em nível integrada às demais medidas de controle pode ser considerada como obra indispensável.

A dinamização de processos erosivos lineares tem sua gênese e evolução associadas primeiramente às características físicas da área, estando envolvidos principalmente os atributos geológicos, pedológicos, a cobertura vegetal e o clima (Bigarella 1996). Entretanto, a influência antrópica atua como agente catalisador, através do manejo inadequado do solo e também da expansão das áreas urbanas sem o devido planejamento (Fendrich et al. 1997).

As formas erosivas tendem a ganhar destaque quando se encontram em contato com áreas urbanas. Em geral, tem-se que sua dinamização pode estar associada a falhas no planejamento urbano, entre as quais cita-se o avanço da urbanização sobre áreas de fragilidade. Nessas condições, as modificações na fisionomia da paisagem funcionam como condicionantes da fisiologia, que irá responder a tais alterações com a intensificação dos processos erosivos.

Nos casos em que são realizadas obras de controle de erosão adotando-se a técnica do terraceamento, podem ocorrer situações em que a ausência de outras medidas na recuperação da área ocasiona a retomada erosiva. Nesses casos, o modelado tecnogênico representado pelos terraços tende a colaborar com a dinamização dos 
processos de erosão linear mediante o condicionamento do fluxo do escoamento superficial e subsuperficial.

As colocações apontadas se evidenciam nos estudos realizados por Mathias (2011) na bacia do córrego Tucunzinho, área localizada nas periferias do sítio urbano do município de São Pedro, na região central do estado de São Paulo. Na área em questão constata-se a ocorrência de formas erosivas cuja dinamização é associada à interação entre os atributos físicos e as intervenções antrópicas, em especial as obras de caráter corretivo, as quais, dadas as circunstâncias específicas da área, têm atuado como condicionantes para a retomada da erosão.

A bacia do córrego Tucunzinho caracteriza-se por apresentar litologias sedimentares representadas pelos arenitos da Formação Pirambóia, originados em ambiente de sedimentação flúvio-lacustre (Triássico), constituindo rochas altamente friáveis. Associada a tal litologia, tem-se a presença de Argissolos e Neossolos Quartzarênicos, que possuem textura arenosa, alto grau de acidez e dificuldade em reter água e nutrientes, o que lhes confere limitações ao uso agrícola e uma grande suscetibilidade a intensos processos erosivos (Sanchez 1971, Carpi Jr 1996, Oliveira 1999).

Entre as formas de relevo observadas na área, as mais notáveis são aquelas associadas à dinamização erosiva, caracterizadas pelo avanço de uma voçoroca de porte considerável, contendo diversos ravinamentos laterais. As vertentes apresentam-se como longas rampas, cujo gradiente clinográfico se eleva abruptamente nos taludes da forma erosiva. Tal fato se configura como colaborador na dinamização dos processos, uma vez que o escoamento superficial tende a ganhar energia, atingindo o talvegue com grande potencial erosivo (Mathias 2011).

O uso do solo na área se caracteriza pelo avanço da urbanização sobre áreas de antigas pastagens

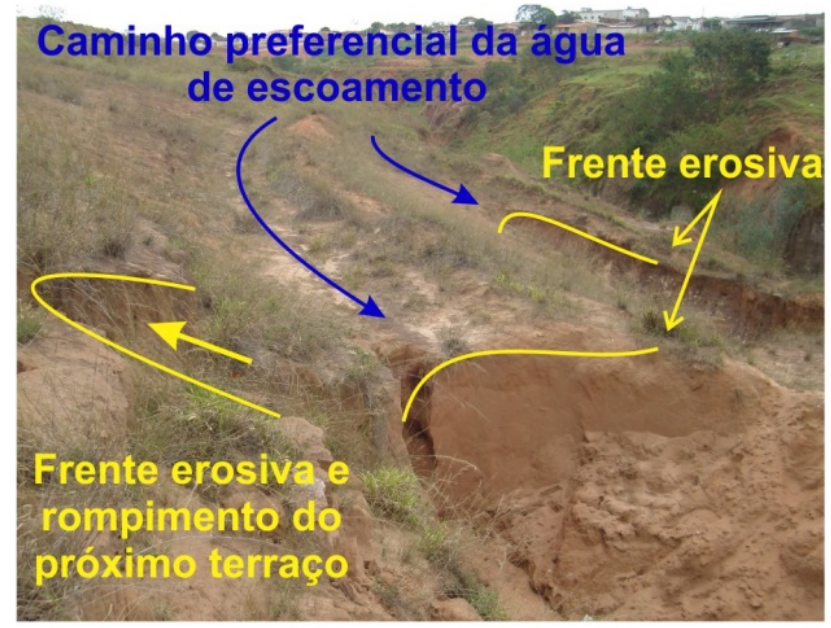

degradadas. A esse respeito convém destacar que a infraestrutura urbana pode ser apontada como contribuinte na retomada erosiva, uma vez que os arruamentos direcionam o fluxo do escoamento superficial diretamente para o interior da bacia, potencializando os efeitos erosivos. A presença de estruturas de microdrenagem inadequadas também se constitui como um contribuinte na dinâmica processual, mediante galerias pluviais que deságuam no leito da voçoroca (Mathias; Cunha 2012). Sendo os setores periurbanos caracterizados por apresentar cobertura vegetacional limitada a gramíneas e formações rupestres, tem-se um quadro de intensa fragilidade ambiental.

Fato marcante na fisionomia da paisagem da bacia é a ocorrência de relevos tecnogênicos associados a obras pretéritas de contenção dos processos erosivos. Em relação às obras citadas, cabe salientar que foram executadas no ano de 1992, constituindo-se no recobrimento das formas erosivas com material inconsolidado removido das áreas de entorno, bem como a concepção de terraços em nível. Ressalta-se o caráter incipiente de tais intervenções, uma vez que se verifica a ampla retomada dos processos erosivos (Facincani 1995, Carpi Jr 1996).

As intervenções ocorrentes na bacia respondem pela elaboração de formas caraterísticas de relevos tecnogênicos, a exemplo dos terraços citados; alteração dos materiais de cobertura mediante a desestruturação dos horizontes superficiais do solo; e criação de depósitos tecnogênicos, expressos nos locais de soterramento das formas erosivas e nas áreas de sedimentação dos materiais erodidos. Entretanto, um dos fenômenos mais marcantes é o condicionamento exercido pelo relevo tecnogênico na retomada dos processos erosivos, conforme se encontra indicado nas figuras $4 \mathrm{a}$ e $4 \mathrm{~b}$.

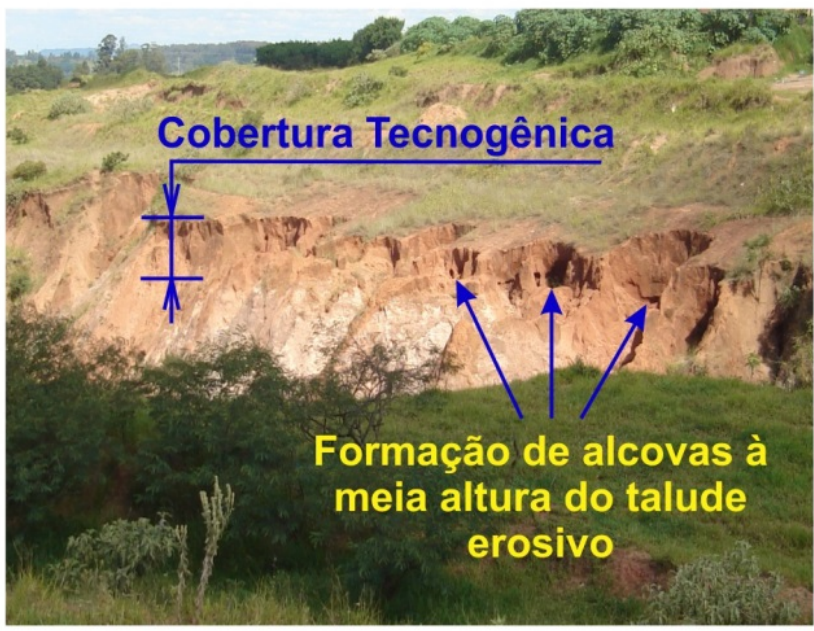

Figuras 4a e 4b: Vetores erosivos e descontinuidade erosiva condicionados pelas coberturas e relevos tecnogênicos, respectivamente. Fonte: Mathias \& Cunha (2012)

De acordo com Mathias \& Cunha (2012) constata-se, em relação à influência das feições tecnogênicas, a concentração das águas de escoamento estimulada pela presença dos terraços, as quais tendem a seguir sentido paralelo ao rebordo da voçoroca, desembocando nas ramificações laterais da mesma (figura 4a). Tal fenômeno atua por meio da retirada e transporte de partículas ao longo das linhas de concentração do fluxo e pela retirada de material na base das cascatas 
formadas na cabeceira dos ramos, produzindo as alcovas de regressão.

Aponta-se ainda que a concentração da água do escoamento no dique dos terraços, em setores onde a mesma permanece estagnada (conforme observações efetuadas pelo autor citado), pode estar contribuindo para a dinâmica subsuperficial mediante o deslocamento de partículas por percolação.

A retomada erosiva é igualmente estimulada pelas características do material de cobertura, o qual tende a permitir a ocorrência de descontinuidade erosiva no contato com a litologia, a exemplo do que se observa na figura $4 \mathrm{~b}$.

O caso apresentado, portanto, demonstra de que maneira os relevos tecnogênicos podem influenciar a retomada de processos erosivos. Cabe salientar que as características dos materiais que compõem as coberturas tecnogênicas são também contribuintes na dinâmica processual que se verifica atuante na área. Tais fatos demonstram a necessidade de um melhor entendimento acerca dos fenômenos envolvidos no contexto de áreas intensamente antropizadas, visando gerar subsídios a intervenções de caráter corretivo que venham a ser efetuadas.

\section{Estudo de caso: Residencial Maré Mansa e Vila Nova Prudente, Presidente Prudente-SP}

O município de Presidente Prudente localiza-se na morfoestrutura da Bacia Sedimentar do Paraná e na morfoescultura do Planalto Ocidental Paulista (Ross \& Moroz 1997). De acordo com o IPT (1981), na região de Presidente Prudente predominam as rochas sedimentares (arenitos) da Formação Adamantina (Cretáceo Superior), pertencente ao Grupo Bauru. Com relação às características da Formação Adamantina, cabe mencionar a presença de bancos de arenito com granulação fina a muito fina (Soares 1980 apud IPT 1981). A partir desta rocha formam-se os tipos de solos encontrados na região.

Contudo, de acordo com Nunes et al. (2006), o relevo também possui influência nos tipos de solos, sendo que, em geral, nas áreas de maior declividade prevalecem os Argissolos Vermelho-Amarelos e os Neossolos Regolíticos de pouca profundidade; Latossolos Vermelhos em áreas de topos; e solos Hidromórficos (Planossolos e Gleissolos) em áreas de planícies aluviais. De acordo com estes mesmos autores, na região há o predomínio de colinas médias e baixas, com altitudes variando entre 300 e 600 metros e declividades entre $10 \%$ e $20 \%$.

Apesar de apresentar estas características físicas, a ação humana tem modificado aspectos dos solos e dos compartimentos do relevo. Entre os exemplos podem ser citadas as formações de depósitos tecnogênicos na Vila Nova Prudente e no Residencial Maré Mansa.

A Vila Nova Prudente foi implantada/legalizada em 1964 (Sposito 1990), e é um dos bairros mais distantes da área central de Presidente Prudente, cujo acesso ocorre pela rodovia Raposo Tavares (SP-270). Apresenta ocupação destinada ao uso residencial e, nas proximidades da planície aluvial, uso voltado à criação de gado.

Devido às alterações humanas causadas na planície aluvial, principalmente a deposição de materiais de construção e outros resíduos (figura 6), além da falta da cobertura vegetal original, esta planície pode ser denominada como planície tecnogênica (Peloggia 1998). Cabe lembrar que estes materiais de construção são classificados como úrbicos, e os outros resíduos, quando da presença de matéria orgânica, são materiais gárbicos.

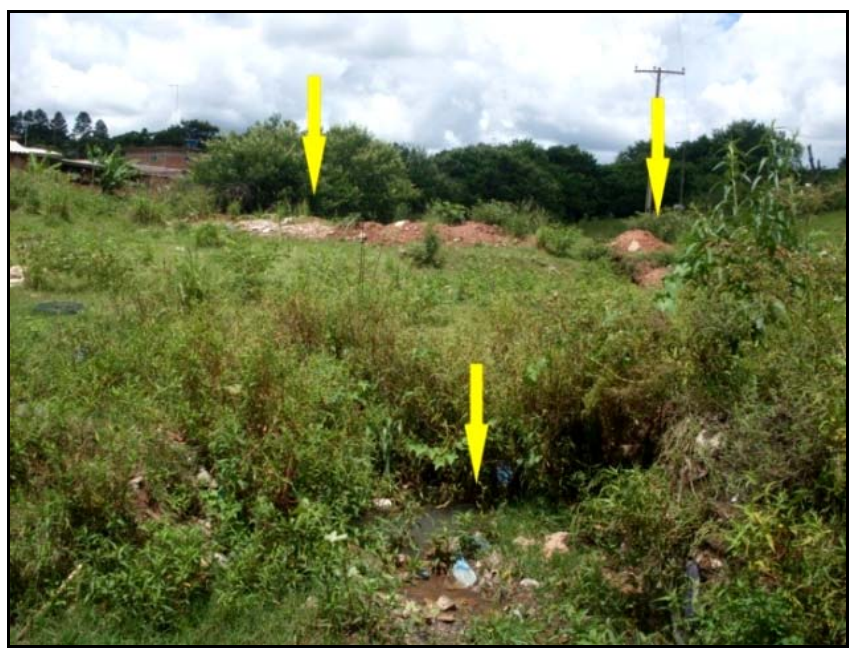

Figura 6: Deposição de resíduos sólidos na planície tecnogênica na Vila Nova Prudente. Fonte: Silva (2012)

Desta forma, verifica-se a existência de um compartimento do relevo tecnogênico (figura 7), no qual há a presença de depósitos tecnogênicos e o aterramento completo de um afluente do córrego do Cedro que, segundo a base planialtimétrica cedida pela Prefeitura Municipal, deveria estar presente no local.

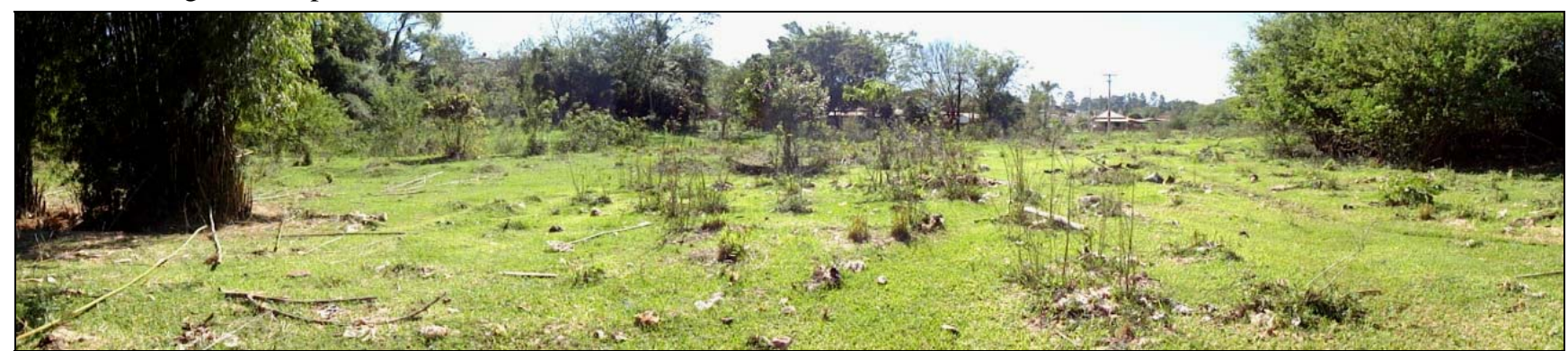

Figura 7: Área da planície tecnogênica na Vila Nova Prudente. Nota-se a ausência do curso d’água. Fonte: Silva (2012)

Na planície, ao contrário dos solos comumente encontrados neste compartimento do relevo (solos hidromórficos), foi reconhecida a formação de depósito tecnogênico. Este se apresentou extremamente arenoso, 
inclusive com presença de areia grossa e muito grossa (Silva 2012). Isto pode ser relacionado principalmente aos materiais de construção depositados no interior da planície tecnogênica, pois, de acordo com a caracterização geológica da região, o arenito da Formação Adamantina apresenta granulação de fina a muito fina. Portanto, parte dos sedimentos que compõem esta planície advém de materiais de construção (materiais úrbicos) e não somente dos horizontes dos solos das áreas de topo e vertentes próximos que podem ter sido remobilizados para o interior da planície devido a processos erosivos intensificados pela falta da cobertura vegetal arbórea, ou mesmo, por processos de terraplanagem na área que atualmente apresenta uso residencial.

Outro caso de alteração nas características do relevo e dos materiais superficiais é o depósito tecnogênico em área de vertente no residencial Maré Mansa. Este bairro possui implantação mais recente, datando do ano de 1998 (Silva 2005).

Uma questão particular deste local foi o processo de recomposição da Área de Preservação Permanente, inclusive com a reconstituição da própria vertente (figura 8), sendo a compactação verificada no corpo do depósito tecnogênico um dos indícios da ação humana no local.

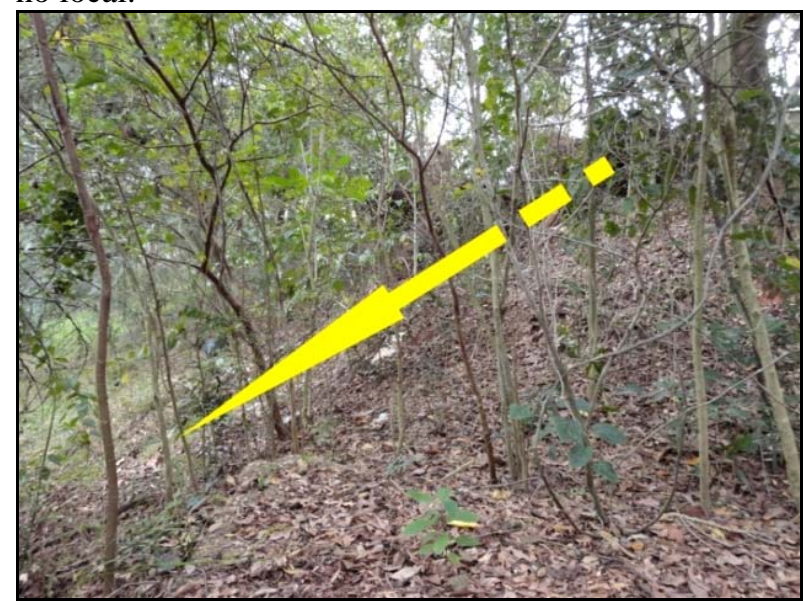

Figura 8: Área de recuperação da vegetação ao longo do córrego da Malandra no Res. Maré Mansa Fonte: Silva (2012)

Apesar do processo de recuperação da área, esta vertente também é um exemplo de relevo tecnogênico, pois suas características foram reconstituídas através da ação humana, bem como os sedimentos presentes na vertente formam um depósito tecnogênico, apesar de suas camadas apresentarem características visuais dos Latossolos presentes na região, em especial com relação à cor. Esta classe de solo foi a que provavelmente serviu de material de empréstimo para a reconstituição. No interior do depósito também foram encontrados resquícios de materiais de construção, no entanto, em menor quantidade que na planície tecnogênica da Vila Nova Prudente. Desta forma, o material sedimentar que atualmente constitui a vertente pode ser classificado como espólico.

Os dois exemplos trabalhados em Presidente Prudente demonstram a formação de depósitos tecnogênicos com características distintas e a constituição de relevos tecnogênicos. No primeiro caso, uma planície tecnogênica, e no segundo uma vertente recomposta por material tecnogênico. Contudo, cabe ressaltar que mesmo que ocorra futuramente a recuperação da cobertura vegetal e de outras características da planície na Vila Nova Prudente, os materiais presentes serão testemunhos da ação humana no local, como é o caso da vertente próxima ao córrego da Malandra no Residencial Maré Mansa.

\section{Análise comparativa entre os estudos de caso}

Os casos apresentados constituem alterações nos compartimentos do relevo e nos materiais superficiais através da gênese dos depósitos tecnogênicos. Estas alterações ocorrem na fisiologia e fisionomia das paisagens.

De modo geral, as intervenções realizadas durante o processo de uso-ocupação do solo modificaram as dinâmicas naturais, especialmente aquelas relacionadas aos fluxos de escoamento superficial e aos processos geomorfológicos (erosão, transporte e deposição), resultando na gênese de novas feições, denominada de morfotecnogênese.

A retirada da cobertura vegetal para a construção dos loteamentos e arruamentos resultou em um maior aporte de sedimentos, depositados em áreas de fundo de vale. Este fato pôde ser observado no Jardim Fonte Nova, localizado no município de Goiânia. A área encontra-se em processo de consolidação, dada a existência de inúmeros lotes vazios, situados nos topos planos.

Os arruamentos, implantados no sentido topovertente, contribuíram para o direcionamento do escoamento das águas pluviais, responsável pelo transporte dos sedimentos, remobilizados de montante para jusante. Em sentido análogo, observa-se na área situada na bacia do córrego Tucunzinho a intrínseca relação entre a implantação dos arruamentos e terraços em nível no redirecionamento dos fluxos superficiais. Neste caso em particular, tais intervenções contribuíram para a aceleração do processo erosivo. A ausência de medidas efetivas para o controle do escoamento superficial, no contexto das morfologias tecnogênicas, resultou na deflagração de um quadro no qual tais intervenções passaram a estimular a retomada da erosão.

Com relação às formas agradacionais, observa-se a presença de diferentes materiais constitutivos compondo os depósitos tecnogênicos, como no caso da planície tecnogênica identificada na Vila Nova Prudente, no município de Presidente Prudente. Neste caso, foram encontrados materiais úrbicos em meio às camadas sedimentares, relacionados aos processos de uso e ocupação a montante, no qual os lotes encontram-se edificados. Este fato também pôde ser observado no Setor Morada do Sol, em Goiânia, onde a área de planície também apresenta a ocorrência deste tipo de material. Contudo, tais áreas se diferenciam 
pelas modificações ocorridas na dinâmica fluvial, uma vez que o afluente do Córrego do Cedro, na Vila Nova Prudente, encontra-se completamente assoreado por materiais tecnogênicos. Em contrapartida, o córrego da Divisa, no Setor Morada do Sol, apresenta intensa ocupação na área da planície, resultando na formação de depósitos tecnogênicos às margens do curso d’água.

Ainda, no tocante aos materiais constitutivos dos depósitos tecnogênicos, observou-se a ocorrência de materiais espólicos depositados no intuito de promover a recuperação de áreas degradadas. No caso da área situada no Residencial Maré Mansa, na cidade de Presidente Prudente, os materiais espólicos auxiliaram na recuperação de um segmento da vertente que, posteriormente, teve sua cobertura vegetal reconstituída com espécies arbóreas. Assim, houve uma tentativa de recuperação de uma área que se encontrava degradada, em especial pela escassa presença da cobertura vegetal próxima à área do fundo de vale, potencializando processos erosivos em vertente e aporte de sedimentos no curso d'água. Em contrapartida, no caso da área peri-urbana localizada no município de São Pedro, foram utilizados materiais retirados das áreas do entorno para recobrimento das feições erosivas. No entanto, como não foram implantadas medidas mitigadoras no sentido de conter o processo erosivo, estes materiais foram carreados para jusante, não resolvendo o problema da erosão.

\section{Conclusões}

Os estudos de caso apresentados exemplificam o modo como a ação antrópica pode alterar os processos e feições geomorfológicas e os materiais superficiais, em especial com a formação de depósitos tecnogênicos. Estes podem se formar a partir de diferentes processos, bem como se constituírem de materiais orgânicos, minerais e manufaturados. Contudo, faz-se necessária a compreensão do histórico de uso e ocupação do solo para o entendimento da ação antrópica e seus resultados na paisagem.

Na apresentação e comparação dos estudos de caso, observa-se a deposição de materiais tecnogênicos nas planícies aluviais e setores da vertente devido às alterações antrópicas na dinâmica natural, como a retirada da cobertura vegetal e consequente potencialização de processos erosivos em setores a montante das deposições, assim como deposições diretas de sedimentos e materiais manufaturados. De forma breve, foram realizados levantamentos das formas de uso e ocupação do solo nas áreas de estudo, como subsídio para a compreensão das coberturas e depósitos tecnogênicos, das feições e relevos tecnogênicos, caso das erosões antrópicas e planícies tecnogênicas, bem como dos processos, naturais e antrópicos, responsáveis pela configuração da paisagem.

Por fim, ressalta-se, com base nos estudos de caso apresentados, que a ocorrência de formações tecnogênicas em ambientes urbanos e periurbanos é cada vez mais comum, considerando-se que as técnicas utilizadas nos processos de uso-ocupação do solo alteram as dinâmicas naturais. Tais formações constituem uma das formas de materialização da ação antrópica sobre a natureza ao longo do tempo. A magnitude e a frequência destas formações nos ambientes antropizados coadunam-se com a proposição de um novo período geológico, o Quinário, no qual os efeitos das ações antrópicas sobre as dinâmicas e processos naturais se ampliam e diversificam.

\section{Agradecimentos}

À FAPESP (Fundação de Amparo à Pesquisa do Estado de São Paulo).

\section{Referências}

Ab’Saber A.N. 1969. Um conceito de geomorfologia a serviço das pesquisas sobre o Quaternário. Geomorfologia, 18:1-15.

Bertoni J., Lombardi Neto F. 1999. Conservação do Solo. Ícone, São Paulo, 355p.

Bigarella J.J., Becker R. D., Passos E. 1996. Estrutura e origem das paisagens tropicais e subtropicais. Ed. UFSC, Florianópolis, 875p.

Campos J.E.G., Rodrigues A.P., Almeida L., Resende L., Magalhães L.F., Sá M.A.M. 2003. Diagnóstico Hidrogeológico da Região de Goiânia. Superintendência de Geologia e Mineração, Goiânia, 87p.

Carpi Jr S. 1996. Técnicas cartográficas aplicadas à dinâmica da bacia do Ribeirão Araquá - SP. Dissertação de Mestrado. PósGraduação em Geografia, Instituto de Geociências e Ciências Exatas, Universidade Estadual Paulista, 188p.

Casseti V. 1992. Geomorfologia do Município de Goiânia. Boletim Goiano de Geografia, 12 (1): 65-85.

Cunha B.C.C. 2000. Impactos Sócio-ambientais Decorrentes da Ocupação da Planície de Inundação do Ribeirão Anicuns: O caso da Vila Roriz. Dissertação de Mestrado. Pós-Graduação em Geografia, Instituto de Estudos Socioambientais, Universidade Federal de Goiás, 207p.

Dias M.B.G. 2013. A Geomorfologia Urbana e os Depósitos Tecnogênicos: Aspectos Teórico-Metodológicos e Estudo de Caso. Anais do Simpósio Brasileiro de Geografia Física Aplicada, 15:57-66.

Facincani E.M. 1995. Influência da estrutura e tectônica no desenvolvimento das boçorocas da região de São Pedro: proposta de reabilitação e aspectos jurídico-institucionais correlatos. Dissertação de Mestrado. Pós-Graduação em Geografia, Instituto de Geociências e Ciências Exatas, Universidade Estadual Paulista, 124p.

Fanning D.J., Fanning M.C.B. 1989. Soil: morphology, genesis and classification. New York, John Wiley \& Sons, 393p.

Fendrich R., Obladen N.I., Aisse M.M., Garcias C.M. 1997. Drenagem e controle da erosão urbana. Champagnat, Curitiba, 486p.

IPT - Instituto de Pesquisas Tecnológicas do Estado de São Paulo. 1981. (São Paulo). Estado de São Paulo, Mapa Geológico, escala 1:500.000.

Mathias D.T. 2011. Propostas de recuperação de áreas peri-urbanas erodidas com base em parâmetros hidrológicos e geomorfológicos: Córrego Tucunzinho (São Pedro/SP). Dissertação de Mestrado. Pós-Graduação em Geografia, Instituto de Geociências e Ciências Exatas, Universidade Estadual Paulista, 128p.

Mathias D.T., Cunha C.M.L. 2012. Condicionantes antropogênicos na evolução de processos de erosão linear acelerada: Córrego Tucunzinho (São Pedro/SP). Anais do Congresso Brasileiro sobre Desastres Naturais, 1:1-10.

Nir D. 1983. Man, a geomorphological agent: An introduction to anthropic geomorphology. Keter, Jerusalem and Reidel, Dordrecht, 165p.

Nolasco M.C. 1998. Depósitos Antrópicos/Tecnogênicos: um conceito em discussão na Geologia. Monografia de Qualificação 
de Doutorado. Pós-Graduação em Geologia, Instituto de Geociências, Universidade Federal do Rio Grande do Sul, 63p.

Nunes J.O.R., Freire R., Perez I.U. 2006. Mapeamento Geomorfológico do perímetro urbano do município de Presidente Prudente-SP. Anais do Simpósio Nacional de Geomorfologia; I.A.G. Regional Conference on Geomorfology, 1-11.

Oliveira A.M.S. 1990. Depósitos tecnogênicos associados à erosão atual. Anais do Congresso Brasileiro de Geologia de Engenharia, 1:411-416.

Oliveira A.M.S. 1995. A Abordagem Geotecnogênica: a Geologia de Engenharia no Quinário. In: Bitar O.Y. (coord.). Curso de Geologia aplicada ao Meio Ambiente. ABGE: IPT, São Paulo, 231-241 p.

Oliveira J.B. 1999. Solos do Estado de São Paulo: descrição das classes registradas no mapa pedológico. Boletim Científico 45, IAC, Campinas, 112p.

Oliveira A.M.S., Brannstrom C., Nolasco M.C., Peloggia A.U.G., Peixoto M.N.O., Coltrinari L. 2005. Tecnógeno: registros da ação geológica do homem. In: Souza C.R.G., Suguio K., Oliveira A.M.S., Oliveira P.E. (Ed.). Quaternário do Brasil. ABEQUA/Holos, São Paulo, 363-378p.

Peloggia A.U.G. 1996. Delineação e aprofundamento temático da geologia do tecnógeno do município de São Paulo: as consequiências geológicas da ação do homem sobre a natureza e as determinações geológicas da ação humana em suas particularidades referentes à precária ocupação urbana. Tese de Doutorado. Pós-Graduação em Geociências, Instituto de Geociências, Universidade de São Paulo, 162p.

Peloggia A.U.G. 1998. O homem e o ambiente geológico: geologia, sociedade e ocupação urbana no município de São Paulo. Xamã, São Paulo, 271p.

Peloggia A.U.G. 1999. Sobre a classificação, enquadramento estratigráfico e cartografação dos solos e depósitos tecnogênicos. In: Peloggia A.U.G. Manual Geotécnico 3: Estudos de Geotécnica e Geologia Urbana. São Paulo, 1:35-50.

Peloggia A.U.G. 2003. O problema estratigráfico dos depósitos tecnogênicos. Citação de referencias e documentos eletrônicos. Disponível

em: http://www.abequa.org.br/trabalhos/projeto_43.pdf Acessado em 05 de maio de 2012.

Peloggia, A.U.G. 2005. A cidade, as vertentes e as várzeas: A transformação do relevo pela ação do homem no município de São Paulo. Revista do Departamento de Geografia, 16:24-31.

Peloggia, A.U.G., Oliveira A.M.S. 2005. Tecnógeno: um novo campo de estudos das Geociências. Anais do Congresso da Associação Brasileira de Estudo do Quaternário, 1:4.

Rohde G.M. 2005. Epistemologia Ambiental: uma abordagem filosófico-científica sobre a efetuação humana alopoiética. EDIPUCRS, Porto Alegre, 407p.

Ross J.L.S., Moroz I.C. 1997. Mapa Geomorfológico do Estado de São Paulo. São Paulo, IPT/FAPESP, 1 mapa geomorfológico, escala 1:1000000.

Sanchez M.C. 1971. Contribuição ao conhecimento das bases naturais dos municípios de São Pedro e Charqueada (SP). Notícia Geomorfológica, 11(21):47-60.

Silva E.C.N. 2012. Formação de depósitos tecnogênicos e relações com o uso e ocupação do solo no perímetro urbano de Presidente Prudente - SP. Dissertação de Mestrado. Pós-Graduação em Geografia, Faculdade de Ciências e Tecnologia, Universidade Estadual Paulista, 183p.

Silva R.B. 2005. Segregação e/ou integração: O Programa de Desfavelamento e Loteamentos Urbanizados em Presidente Prudente. Dissertação de Mestrado. Pós-Graduação em Geografia, Faculdade de Ciências e Tecnologia, Universidade Estadual Paulista, 130p.

Sposito E.S. 1990. Produção e apropriação da renda fundiária urbana em Presidente Prudente. Tese de Doutorado. Pós-Graduação em Geografia Humana, Faculdade de Filosofia, Letras e Ciências Humanas, Universidade de São Paulo, 230p.

Ter-Stepanian G. 1988. Beginning of the Technogene. Bulletin I.A.E.G., 38:133-142.

' Recebido 29 de novembro de 2013 Aceito 04 de abril de 2014 